\title{
GHANA MENTAL HEALTH ACT 846 2012: A QUALITATIVE STUDY OF THE CHALLENGES AND PRIORITIES FOR IMPLEMENTATION
}

\author{
G. H. WALKER \\ 26 Ash Road, Leeds, LS6 3JF, UK
}

DOI: http://dx.doi.org/10.4314/gmj.v49i4.8

Corresponding Author: Dr. George Hudson Walker

Email:ghw@doctors.net.uk

Conflict of Interest: None declared

\section{SUMMARY}

Objectives: This study aims to describe the views of key stakeholders in mental health in Ghana on the challenges faced with regard to the implementation of, and priorities for implementation of, the 2012 Mental Health Act of Ghana.

Design: A cross-sectional qualitative study with 12 participants, using semi-structured interviews.

Setting: Greater Accra Region.

Participants: The study population consisted of three groups; Members of the Mental Health Authority Board (MHAB), Providers of Mental Health Care working for the Mental Health Authority and Representatives of non-governmental and educational organisations working in mental health, Four participants were identified from each group.

Interventions: Not Available

Main outcome measures: The interviews, subsequent analysis and output were based around three main topics of discussion: awareness of the Act, challenges to the implementation of the Act, and priorities for implementation.

Results: Challenges identified include: financial limitations, the limited dissemination of the act, delays in the approval of the Legislative Instrument by the Attorney General's Department, losing access to patients in non-orthodox mental health facilities, inadequate resources for implementation, legal infrastructure, timeframe, and the lack of a physical presence for the new Mental Health Authority. Suggested priorities for implementation include: development of human and financial resources, education, passing of the LI (Legislative Instrument), infrastructure development and human rights protection.

Conclusions: Challenges identified in this study are likely to be applicable to other nations seeking to implement modern Mental Health Legislation. Key stakeholders in the mental health system showed broad concordance in the immediate priorities for Ghana's Mental Health System.
Keywords: Mental health, Psychiatry, Ghana, Mental health legislation, Policy implementation

\section{INTRODUCTION}

The global importance of mental disorder

Mental disorder accounts for 14\% of the global burden of disease. ${ }^{1}$ It is an essential component of health, and is both a risk-factor for, and co-morbidity of many physical and infectious diseases. ${ }^{2}$ Despite this mental health care has only been recognised as a global priority in the last decade.

Within Africa, many countries lack a mental health policy. The stigma which faces persons living with mental disorder as well as the lack of access to services means many go without treatment, whilst others seek help from traditional and faith healers ${ }^{7,9}$.

\section{Mental Health in Ghana}

In a recent study the prevalence of moderate or severe psychological distress in Ghana was found to be $18.7 \%$, this need for care is not being addressed by the current system. ${ }^{10,12}$

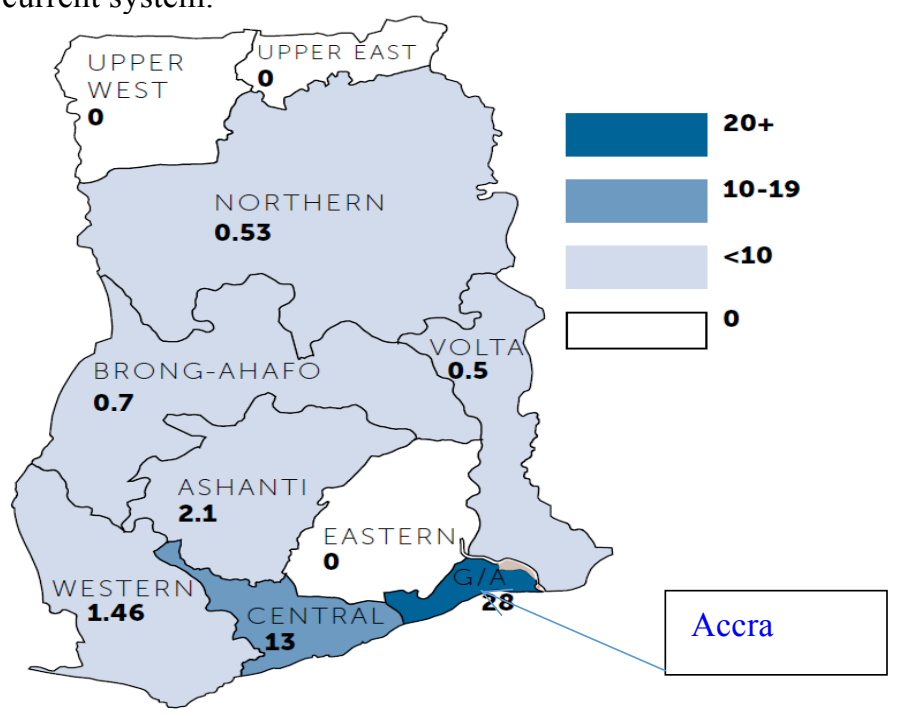

Figure 1 Inpatient beds per 100,000 populations, by region. From (10). 
Mental health services are clustered in the south where the three main psychiatric institutions are located (Figure 1). Recent literature cites problems of human resources, medicines, funding, geographic inequities and human rights. $10,13,14$

Mental health policy in Ghana has historically been unfeasible and poorly implemented. ${ }^{14-17}$ In 2012, after six years of deliberation by parliament, the Government of Ghana enacted the Mental Health Act (MHA 2012). ${ }^{18}$ This Act - praised as an example of WHO best practice - promises Ghana a high quality, accessible, affordable and sustainable mental healthcare system which moves away from the southern institution based care system in place at the moment. ${ }^{19}$

Doku et al foresaw several challenges relating to the implementation of the mental health act, including those of human resources, finances and the legal system. Two years on from the passing of the act, and 6 months after the formation of the mental health authority board it is time to examine the perspectives of the people within the mental health system and related civil society environment, so that challenges to the implementation of the Act can be identified and prioritisation of key actions can occur.

By documenting the challenges facing the management, frontline staff and wider stakeholders in trying to implement a new mental health act, it is hoped that the understanding of the process of the development and implementation of mental health legislation in the developing country context will be furthered. Furthermore, other countries who may look to Ghana as an example in future may be better equipped and prepared for the challenges which face them.

\section{Aim}

Through consideration of the views of practitioners, leaders in mental health as well as those working in associated NGOs (Non-Governmental Organisations), this study aims to produce four clear recommendations for action which will allow for the Mental Health Act to be better implemented.

\section{Objectives}

To outline the extent to which study participants are aware of the MHA 2012; To describe the challenges and priorities for the implementation of the MHA 2012 and To produce recommendations for action towards the implementation of the Act.

\section{METHODS}

\section{Study design}

The study was cross-sectional and qualitative in design. The University of Leeds and the Accra Psychiatric Hospital granted ethical approval.

The study population consisted of three groups: Members of the Mental Health Authority Board (MHAB), Providers of Mental Health Care working for the Mental Health Authority, Representatives of nongovernmental and educational organisations working in mental health.

A sample size of 12 participants was feasible under the given constraints. Using convenience sampling, four participants were drawn from each of the three groups of the population. The Chief Psychiatrist, who acted as a gatekeeper and research host, identified the participants.

\section{Data collection}

Participants were given information sheets in advance of interviews, and signed consent forms before interviews took place - see appendix . ${ }^{1,2}$ Semi-structured interviews were completed with all participants according to an interview guide which probed topics related to the aims of the study. Participants were given the opportunity to raise any further topics not discussed at the end of the study.

The interviews took place in the capital city Accra (Figure 2), over a two-week period in May 2014 and were recorded electronically. The participants were given the option to either remain anonymous or give a name/title to be used for the purposes of analysis and dissemination. The interviews lasted between 22 and 48 minutes (mean: 27 minutes) and were conducted in English.

\section{Data analysis}

The interviews were transcribed verbatim into QSR Nvivo $10 .^{20}$ Four participants opted to review their transcripts after the interview. Familiarisation with the data was achieved through the re-listening of each interview with the transcripts at hand.

Thematic analysis was chosen as an analysis methodology which would facilitate the creation of a rich and detailed account of the full range of experiences expressed by the relatively small sample size. ${ }^{21}$ The data was coded according to "in-vivo" or emergent themes drawn from the participants own responses. 
Once all of the data had been coded, the emergent themes were reviewed - some were then aggregated into "umbrella" themes which encompassed several related themes."

A priori" or pre-determined codes were used to classify the emergent and aggregated codes into theme categories relevant to the aims of the study (Table 1). The findings in this report are structured by the themes which emerged which address each aim of the study.

Table 1 Extract from coding scheme.

\begin{tabular}{|l|l|l|}
\hline Emergent code & Aggregated code & $\begin{array}{l}\text { Pre-defined code } \\
\text { category }\end{array}$ \\
\cline { 1 - 2 } $\begin{array}{l}\text { Improve medicines } \\
\text { supply chain }\end{array}$ & $\begin{array}{l}\text { Developing infra- } \\
\text { structure for the } \\
\text { delivery of mental } \\
\text { health care }\end{array}$ & \\
\cline { 1 - 1 } $\begin{array}{l}\text { Make mental health } \\
\text { care more accessible }\end{array}$ & \\
\cline { 1 - 2 } $\begin{array}{l}\text { Improve mental health } \\
\text { facilities }\end{array}$ & & \\
\cline { 1 - 2 } $\begin{array}{l}\text { Operationalising "clear } \\
\text { the streets" }\end{array}$ & & Barriers \\
\hline Global financial crisis & Financial & \\
\hline
\end{tabular}

\section{Limitations}

The sample size of 12 , along with the heterogeneity of the sub-groups meant that the complete range of experiences of the study population was likely not documented. The results of this research are therefore not generalizable to the whole population studied. As the participants were all selected by the Chief Psychiatrist there may have been bias towards those who hold particular views.

As participants have a vested interest in furthering the cause of mental health care in Ghana, the study may have been used as a lobbying platform to express political views or personal/organisational agendas.

This study may also have benefitted from a focus group discussion in which participants may have come to further conclusions relating to the study questions common to all participants.

Triangulation of the findings with other sources such as independent reports and media coverage would also have been of benefit. This study does not attempt to describe the views of stakeholders in mental health from either the North of the capital or from rural areas, where the barriers and priorities may be very different from those in the comparatively well-resourced Accra. Whilst respondent validation was attempted to some extent, it was limited to a small number of participants.

\section{RESULTS}

The sample was made up of people with professional backgrounds in Nursing, Medicine, Social work, Psychology, Zoology, Business and Religion. Five women and seven men were interviewed. The findings in this report are structured by the themes that emerged which address each aim of the study.

\section{Awareness of the Act}

All twelve respondents were aware of the act. Service providers talked about the provisions of the Act relevant to themselves. Members of the board were either involved in the drafting of the Bill or were brought into the authority by the Act itself. Members of mental health NGOs and educational institutions had all been heavily involved in the consultation phase of the act.

\section{Challenges to the implementation of the Act Financial}

Eight respondents made reference to the financial challenge to the implementation of the act. Some respondents stated that no money has been made available for the mental health authority. Some funds have been made available by DFID (UK Department for International Development) - however these funds have conditions attached which prohibit them from being used for certain activities such as building offices. One board member blamed the global financial crisis and Ghana's new LMIC (Lower-Middle Income Country) status for falling support from government and donors.

"The Act has been passed, the authority is supposed to be in place the board has been inaugurated, we are supposed to run but somebody is still holding our legs because we don't have the finances"

Respondent 8

Several respondents stated that although plans have been made and a budget created, the implementation of the Act has been limited by the lack of funding so far. Examples of programmes which have not been implemented due to the lack of funding given included: improving training institutions, training support from overseas, hiring new human resources, building a physical structure for the authority, treatment plans, and creating mental health units in regional and district hospitals.

"The law would have expected a mental health fund to be established and that probably would have, that would have gone a long way to help in the infrastructure development to bring about a more decentralised, a more integrated mental health system"

Mental Health NGO representative 


\section{No barriers}

A senior nurse stated that there is nothing specific slowing the implementation of the Act beyond the expected time taken for a new political agency to begin effecting change, on condition that the education of the public went well.

\section{Limited dissemination}

Three respondents stated that the limited dissemination of theActso far may impact upon its implementation, stressing the need for wider education on its contents and implications for different groups outside of the mental healthcare service.

"I don't think enough information has gotten out about all of those components of the law... for example the CHRAJ [Commission for Human Rights and Administrative Justice], I don't even know if they have a copy"

Educator in mental health, MHAB member

One respondent stated that the media give mental health stories low priority.

\section{Parliament}

Three respondents talked about the parliamentary process as a challenge to the speedy implementation of the act. One board member felt that the time interval between the bureaucratic stages was too long.

“you've got to think about the country's bureaucracies, and that is to say from one step to the next, there is too much time interval."

Respondent 11

Once the LI (Legislative Instrument) is approved by parliament, the board can begin to implement it.

"So what is left now is for the LI to be presented to the republic of Ghana, and then when it is passed then move the authority of the board will now have the mandate to do what we want to do."

Senior Lecturer, MHAB Member

Losing access to patients in traditional or faith-based mental health facilities. There was agreement between respondents that collaboration should be sought with alternate providers of mental health care. Some respondents warned of the potential loss of access to patients if the camps were shut down with immediate effect.

A psychiatry trainee described a group of patients who accessed non-orthodox services because of geographical accessibility or because they were dissatisfied with orthodox treatment who could become unreachable if the camps were all closed. Another healthcare professional cited spiritual beliefs surrounding mental illness as a reason for people using such institutions.

"we can't really force all of them to just stop working at once even though the law is in effect because there is a certain niche and pool of people that we don't have access to that they do have access"

Psychiatry trainee

\section{Inadequate resources}

One mental health educator felt that nurses in the community are not adequately supported in terms of transportation and medicines supply - a view corroborated by other respondents.

" nurses who are not supported by the districts with transportation to go out into the community or medication ... and as we expand services you know the first thing to expand is the use of drugs"

Mental health Educator, Board Member

\section{Legal infrastructure inadequate}

Three respondents cited inadequacies in the preparations of the legal infrastructure which will be required to implement and police the human rights sections of the act, including the fact that the Mental Health Review Tribunals have not yet been created and that lawyers interested in mental health have not made themselves known to mental health services.

"The relevant agencies that are supposed to ensure that the right thing is done as per the law have not been strengthened yet or has not been established yet"

Mental health NGO representative

\section{No physical presence for the $M H A$}

Four respondents - two board members and two NGO representatives - made reference to the lack of a physical space for the mental health authority to use as an office, one going on to say that without it the organogram could not be put into being.

"it means that you need a structure... a physical structure where you say this is the headquarters of mental health ... so you need to build that and that is the challenge, the challenge comes financially."

Respondent 11

Although respondents attributed this to the lack of funding available, they felt that it presents a distinct challenge to overcome. 


\section{Human resources}

Five respondents agreed that the current shortage of trained mental healthcare providers presents a barrier to implementation.

"Now the next problem that everyone faces is the people, people who are supposed to work within the value chain of the mental health, right there are challenges that will come up"

Mental Health NGO Representative

Four respondents commented on the low numbers of psychiatrists, citing the working environment; lack of remuneration for taking on higher-risk work; and stigmatisation of patients and staff as reasons for the shortage.

"it's the same pay - so why not do something that you get more respect for? It's a deprived area with problems"

Psychiatry trainee

Three board members saw the current nationwide ban on hiring new public sector staff as an obstacle to progress.

\section{Limited timeframe}

Two respondents cited the short time since theActwas passed as a challenge and reason why implementation of the Act has not yet been complete, one feeling that this was the only barrier.

"The issue is that the Act just came in 2012, we are now in 2014."

Mental Health NGO Representative

One board member stressed the need to manage the public's expectations of the Authority, as change will take time.

"the political agencies they don't just do things just like that-you need to take your time so I am saying is that if it's to take shape for the next 4/5 years the mental health authority will sit down very well and enjoy it."

Senior Psychiatrist, MHAB Member

\section{Priorities for the implementation of the Act: Human resources}

There was wide consensus that the development of human resources for mental health should be prioritised. "first we have to make sure we train more staff for the program because ... the mental health act, it's more community based ... so we have to train more nurses to go into the community and at the same time the general hospitals now where we have new mental health facility there you need that place to be staffed with nurses"

Psychiatric Nurse

Two respondents spoke of the need to make employment within the mental health service more attractive through improved job security, opportunities for clinicians to undertake governance responsibilities and safer working conditions.

"Already psychiatrists are stigmatised, along with our patients so something I think should be done to attract more people like ... an extra [financial] bonus ... easy accommodation ... some little form of incentives should come in to attract people into the mental health field."

Respondent 6

\section{Securing financing}

Seven respondents spoke of the need to secure finances to use in implementing the provisions of the act. There was consensus building on the discussions of the lack of finances as a barrier around the improvements and progress which could only be made once funding is secured.

"If it is what are the things that must start or the steps to have the law effectively implemented ... we need to have a dedicated fund to finance the human resource shortages, the logistical shortages, issues of medicines and transportation for community health workers"

Mental Health NGO Representative

Suggestions for potential sources of funding included Value Added Tax (VAT), National Health Insurance Scheme (NHIS) and support from government, nongovernmental and international agencies. One respondent suggested that the authority should seek input from persons with expertise in securing funding and lobbying.

"we are also looking at ... government of Ghana direct support ... into donor support ... civil society support ... private sector support. We are also looking into any international support"

Respondent 11 


\section{Education}

Eight respondents spoke of the need to prioritise the education about the content of the Act - target groups mentioned included the general public, families of persons with mental disorder, general healthcare workers and mental healthcare workers. There was agreement that the education should be the result of coordination between government and civil society organisations to maximise penetration, whilst avoiding duplication of efforts.

"We need to hasten, intensify - like hastening the education, going round all regions, calling all regional directors, calling all chiefs, calling all teachers to come together to understand..."

Senior Psychiatric Nurse Coordinator, national level.

Six respondents specified that the public should be educated - some seeing this as a means to reducing stigma; others felt that the training of healthcare providers outside of mental health and legal workers - who will be expected to participate in tribunals - should be a priority. Respondents spoke of the need to make healthcare providers aware of their responsibilities under the act.

"They have to know that once they [persons with mental disorder] are sick ... they do not have to discriminate against them, they have to give them the needed support because if they don't do that then they don't get cured quickly. So we have to first of all get the families and then society [to be educated] ... we are hoping that that would go a long way in curbing the discrimination."

$$
\text { Psychology Educator, MHAB Member }
$$

\section{Advancing the legislative instrument and creating} the Mental Health Authority

Respondents spoke of the passing of the LI and the creation of the authority as two key events for advancement towards implementation.

"The key priority right now is the LI, because it's what defines the governance structure of the authority, that's the key priority ... So how much pressure the board can exert on those working on it - that is what we have got to do now."

Respondent 11

There was agreement that although the passing of the LI would be a faster process than the passing of the Act had been, lobbying and pressure are still key.
"The LI - at the moment we have finished we send it to the government and we will put pressure on government to understand that we need the LI passed as soon as possible and I think that wouldn't take as much time as the Act to place in parliament."

Senior Lecturer, MHAB Member

Two respondents felt that creating a physical space for the authority to work from is a priority.

"one of our priorities is to get that structure, ... when the LI is through - where all these people will sit in to work. So we need that infrastructure"

Respondent 11

\section{Developing infrastructure for service delivery}

Four respondents discussed the infrastructure development that they felt would be necessary to implement the Act as a priority. Respondents suggested that improving existing facilities as well as the building of new facilities should be a priority, with one suggesting that novel ways of improving accessibility of mental health care should also be a priority.

"Almost any form of infrastructure that can sustain and ensure effective service delivery... ...the physical infrastructure, the financial resources, the human resources and all others that are needed."

Mental Health NGO representative

These respondents also felt that the procurement and distribution of psychotropic medications should be a priority.

"the medications are supposed to be free ... so we should spread the drugs also across board and then make it more available we should flood the system with it."

Respondent 6

\section{Priorities relating to the human rights aspects of the Act}

Two respondents suggested priorities for implementation which relate to the legal protection which is to be afforded to persons with mental disorder under the act. One respondent expressed the need to identify and train the members of the judiciary who would be involved in review tribunals. Another called for an inventory of all mental health facilities to facilitate the monitoring of standards of care in orthodox and non-orthodox settings. 
"we need to have an inventory of all mental health facilities both orthodox or not orthodox in Ghana so that they can be reached and assessed"

Senior psychiatrist, MHAB member

\section{DISCUSSION}

\section{Awareness of the Act}

Stakeholders and practitioners working in mental healthcare in Accra are well aware of the 2012 Mental Health Act. This may be a reflection of the study sample which was drawn from around the psychiatric hospital which is currently being used as a base for the new Mental Health Authority - mental healthcare providers in other parts of the country may not have the same level of awareness.

Similarities between perceived barriers and those described in related literature

In common with the concerns expressed by Doku et al. in 2012 and the stakeholders interviewed by Awenva et al. in 2009 the limited financial and human resources are perceived to be major barriers.$^{19,22}$ The long journey from the conception of mental health policies and laws to implementation has been described in literature relating to many parts of the world/continent. Concerns that the legal infrastructure's inadequacies in providing the structures needed to enforce the rights of patients and persons with mental disorder in the community as laid out by the law are shared with Doku et al ${ }^{19}$

Five years on from Awenva's study of stakeholders in mental health in Ghana, the low levels of knowledge of mental health and the Act amongst the public and healthcare professionals are still of concern to stakeholders . ${ }^{22}$

New perspectives on the barriers facing the Mental Health Authority of Ghana

The perspective offered by one respondent that the only barrier is the lack of education about mental health amongst the Ghanaian population has not been described previously and may add gravity to the calls of others for efforts in the field of public mental health education to be improved. ${ }^{13}$

The lack of a physical structure for the Mental Health Authority is now of concern to members of the board this has not previously been raised as an issue.

Progress in overcoming previously described barriers In 2010 Omar et al. reported that across four African nations - one of them Ghana - the draft form of policies (c.f. enactments and publication of finalised plans) and the low priority of mental health contribute to poor implementation; the findings here suggest that is no longer the case - as there was wide support and lobbying for the Act to be passed. However the views expressed by some stakeholders in research completed as part of the Mental Health and Poverty Project in 2008 that mental health care is a priority on paper but not in practice i.e. in terms of resource availability may still be true ${ }^{13}$

The close engagement and consultation between stakeholders and mental health policymakers described by respondents shows that a lack of consultation is no longer a barrier to policy implementation as it was at the time of Awenva et al's study . ${ }^{13,19,22}$

Priorities for implementation in the context of Ghana and Africa

The priorities presented by stakeholders in this study related closely to the recommendations of others in the context of Ghana and related closely to the barriers described. Respondents recognised the rapid development of human resources for mental health and the securing of sustainable funding for the implementation of the Act as priority areas for improvement - in agreement with Doku and Awenva. The legislative instrument is now the last step which needs to be taken in order to provide implementers with the details of funding arrangements and other provisions needed for them to act.

Stakeholders' prioritisation of widespread education agrees with the recommendations of the 2011 WHO AIMS report to prioritise and coordinate mental health promotion . ${ }^{10}$ Finally, the infrastructure development which respondents here have identified as necessary for the advancement of mental health care are consistent with the views of a similar group of stakeholders in $2010^{22}$.

\section{Implications}

If the Mental Health Act is to be fully implemented the political commitments to mental health need to be realised as financial support. Financial resources are needed to allow the creation of a functioning Mental Health Authority which can then go on to develop the human resources and infrastructure needed to provide the services it has been created to provide. The education of the public must then follow to ensure that those who need help seek care, whilst concurrently workers in the health sector, judiciary and social services are briefed on their responsibilities under the act.

Ghana can be looked upon as an example of a country where a locally and internationally consultative process has produced an Act with which key stakeholders are 
highly engaged. It also demonstrates that in a resourcepoor country where mental health was low on the political agenda, sustained and concerted lobbying efforts can bring a bill from conception to enactment.

The role of international donor and technical agencies has not been insignificant in the whole process - if the Act is to be continued to be rolled out, sustained financing and technical resources must be sourced internally.

Finally, as stated by one respondent - it has not been long since the Act was passed, this must be taken into account and considered by other countries in their projections for mental health care.

\section{CONCLUSION}

This study was needed to shed light on the fate of a highly promising progressive example of best practice in mental health legislation in a resource poor country and its potential to overcome longstanding barriers which face many countries in similar settings through focused action in the right domains. It aimed to describe the barriers facing those implementing the Act and to document the stakeholders' views of the areas of effort which need to be prioritised.

Whilst it is still early in the day - two years since the Act was passed, compared with the six years it spent as a bill - it is clear that the longstanding barriers of financial and human resource limitations are keeping the Mental Health Authority from reaching their potential. Key priorities have been identified and recommendations made towards the goal of the Act reaching its potential. Once finances are secured, progress in other domains such as infrastructure and training development can be made. Ghana is therefore at the same time an example of the tremendous progress that can be made in meeting the global need for mental health care, and a warning as to the common pitfalls, which can delay such progress.

\section{RECOMMENDATIONS}

The Legislative Instrument should be passed as soon as possible, and should detail the size and source of the budgetary allocation for the Mental Health Authority. A detailed human resource for mental health development plan should be formulated in conjunction with training institutions in Ghana and overseas in time for the passing of the LI.
A programme of public education should be developed to include information on seeking mental health care and reducing stigma. The plan should be ready in time for the first release of funding.

A detailed plan for the recruitment and training of personnel, as well as the creation of associated materials and resources for the Mental Health Review Tribunals should be drawn up and submitted to the MHAB before the LI is passed.

\section{ACKNOWLEDGEMENT}

With deepest gratitude to Maye Omar, University of Leeds and Dr Akwasi Osei, Chief Psychiatrist who made this work possible.

\section{REFERENCES}

1. WHO. The World Health Report 2001 - Mental Health: New Understanding, New Hope. Geneva: WHO Archive; 2001.

2. Prince M, Patel V, Saxena S, Maj M, Maselko J, Phillips MR, et al. No health without mental health. The Lancet. 2007;370(9590):859-77.

3. Lund C, De Silva M, Plagerson S, Cooper S, Chisholm D, Das J, et al. Poverty and mental disorders: breaking the cycle in low-income and middle-income countries. The lancet. 2011;378(9801):1502-14.

4. Eaton J, McCay L, Semrau M, Chatterjee S, Baingana F, Araya R, et al. Scale up of services for mental health in low-income and middleincome countries. The Lancet. 2011;378(9802):1592-603.

5. Chisholm D, Flisher A, Lund C, Patel V, Saxena $\mathrm{S}$, Thornicroft $\mathrm{G}$, et al. Scale up services for mental disorders: a call for action. The Lancet. 2007;370(9594):1241-52.

6. World Health Organisation. Mental health action plan 2013-2020. Geneva: WHO Library; 2013.

7. McDaid D, Knapp M, Raja S. Barriers in the mind: promoting an economic case for mental health in low-and middle-income countries. World Psychiatry. 2008;7(2):79-86.

8. Saraceno B, van Ommeren M, Batniji R, Cohen A, Gureje O, Mahoney J, et al. Barriers to improvement of mental health services in low-income and middle-income countries. The Lancet. 2007;370(9593):1164-74.

9. Quinn N, Knifton L. Beliefs, stigma and discrimination associated with mental health problems in Uganda: Implications for theory and practice. International Journal of Social Psychiatry. 2013:0020764013504559. 
10. Roberts M, Asare J, Mogan C, Adjase E, Osei A. The mental health system in Ghana - WHO AIMS report. Accra: Kintampo Project / Ghana Ministry of Health; 2013.

11. Sipsma H, Ofori-Atta A, Canavan M, Osei-Akoto I, Udry C, Bradley EH. Poor mental health in Ghana: who is at risk? BMC public health. 2013;13(1):288.

12. Jack H, Canavan M, Ofori-Atta A, Taylor L, Bradley E. Recruitment and Retention of Mental Health Workers in Ghana. PloS one. 2013;8(2):e57940.

13. Doku V, Ofori-Atta A, Akpalu B, Read U, Osei A, Ae-Ngibise K, et al. Phase 1. Country report: a situation analysis of mental health policy development and implementation in Ghana. Phase 1 Country report: a situation analysis of mental health policy development and implementation in Ghana. 2008.

14. Walker G. The mental health system in Ghana: A literature review. Unpublished. 2014.
15. Ministry of Health. Five Year Programme of Work for Mental Health 2007-2011. Accra: Government of the Republic of Ghana; 2007.

16. Ghana Mental Health Decree, (1972).

17. Ministry of Health. Mental Health Policy and Programmes. Accra: Government of the Republic of Ghana; 1994.

18. Mental Health Act, Parliament of the Republic of Ghana(2012).

19. Doku V, Wusu-Takyi A, Awakame J. Implementing the mental health Act in ghana: any challenges ahead? Ghana Med J 2012;46(4):241.

20. QSR International. NVivo 10 2012. Available from: www.qsrinternational.com.

21. Braun V, Clarke V. Using thematic analysis in psychology. Qualitative research in psychology. 2006;3(2):77-101.

22. Awenva A, Read U, Ofori-Attah A, Doku V, Akpalu B, Osei A, et al. From mental health policy development in Ghana to implementation: What are the barriers. African Journal of Psychiatry. 2010;13(3). 